\title{
ATÉ QUANDO PROLONGAR A VIDA?
}

Valeria Silva Galdino Cardin ${ }^{1}$ Lais Moraes Gil Nery ${ }^{2}$

UNTIL WHEN EXTENDING LIFE?

RESUMO: O prolongamento da vida, a obstinação terapêutica, ou seja, a distanásia lesiona os direitos fundamentais, como a autonomia da vontade, a dignidade humana. Os avanços das práticas médicas, no século $X X$, geraram inúmeros benefícios para este campo, porém estes avanços permitiram um controle das funções fisiológicas do paciente, o que gerou a possibilidade de prolongar a vida. A distanásia é o prolongamento desnecessário da vida, que gera angustia, dor, sofrimento para o paciente e seus familiares. O objetivo deste trabalho é a compreensão de como a prática da distanásia, a obstinação terapêutica, o tratamento inútil gera uma lesão aos direitos fundamentais, ou seja, como essa prática fere os princípios da dignidade da pessoa humana, da liberdade, da autonomia da vontade. Trata-se de um estudo realizado por meio de revisão bibliográfica e documental, descritivo e explicativo. O fato de quebrar o ciclo natural da morte, prolongando a vida não proporciona uma morte digna, mas sim, uma morte com sofrimento e dor desnecessários. Nesse último momento é essencial o respeito a autonomia da vontade e a preservação da dignidade humana.

Palavras-chave: Dignidade da Pessoa Humana. Direitos Fundamentais. Distanásia.
ABSTRACT: The prolongation of life, the therapeutic obstinacy, that is, dysthanasia damages fundamental rights, such as the autonomy of the will, human dignity. The advances of medical practices in the twentieth century generated many benefits for this field, but these advances allowed a control of the physiological functions of the patient, which generated the possibility of prolonging life. Dysthanasia is the unnecessary prolongation of life, which generates anguish, pain, suffering for the patient and his relatives. The objective of this work is the understanding of how the practice of dysthanasia, therapeutic obstinacy, useless treatment, generates an injury to fundamental rights, that is, how this practice violates the principles of the dignity of the human person, freedom, autonomy of will. It is a study carried out through a bibliographical and documentary review, descriptive and explanatory. The fact of breaking the natural cycle of death, prolonging life does not provide a worthy death, but a death with unnecessary suffering and pain. At the last moment, it is essential to respect the autonomy of the will and the preservation of human dignity.

Keywords: Dignity of the Human Person. Fundamental rights. Dysthanasia.

\footnotetext{
${ }^{1}$ Pós-doutora em Direito pela Universidade de Lisboa; Doutora e mestre em Direito das Relações Sociais pela Pontifícia Universidade Católica de São Paulo (PUCSP); Docente da Universidade Estadual de Maringá e no Doutorado e Mestrado do Programa de Pós-graduação em Ciências Jurídicas pelo Centro Universitário de Maringá (UNICESUMAR); Pesquisadora e Bolsista Produtividade em Pesquisa do Instituto Cesumar de Ciência, Tecnologia e Inovação (ICETI); Advogada no Paraná.

${ }^{2}$ Mestranda em Ciências Jurídicas pelo Centro Universitário de Maringá (UNICESUMAR); Graduada em Direito pela Faculdade Maringá; Graduada em Enfermagem pela Universidade Estadual de Maringá (UEM); Residência Multiprofissional em Urgência e Emergência, com ênfase em Enfermagem, pela Universidade Estadual de Maringá (UEM).
} 


\section{INTRODUÇÃO}

$\mathrm{O}$ avanço da tecnologia, no século $\mathrm{XX}$, proporcionou grandes benefícios à sociedade, como no controle ou na eliminação de doenças, no avanço de tratamentos para alcançar a cura. Porém, este avanço ocasiona uma diminuição no número de mortes naturais, pois as tecnologias permitem que a vida do paciente seja mantida por meio artificial, de modo indistinto, tornando-se possível controlar suas funções fisiológicas, prolongando a vida mesmo sem ter uma perspectiva de cura.

Este processo de adiar a morte ao máximo, com o emprego de todos os meios disponíveis, sejam eles ordinários ou extraordinários, é denominado de distanásia. São os tratamentos que ocasionam a dor e o sofrimento tanto do paciente como de sua família, um tratamento em que a morte é inevitável e invencível. Diante deste quadro, surgem alguns questionamentos. Até quando é ético evitar a morte a qualquer custo, trazendo mais sofrimento para quem não tem uma perspectiva de vida, quebrando o ciclo natural da morte?

Pretende-se demonstrar como ocorre o desrespeito aos direitos fundamentais na prática da distanásia. Desrespeito aos princípios da dignidade da pessoa humana, da liberdade, da autonomia da vontade. É preciso resguarda o direito a morte digna, sem dor, sem sofrimento, que siga o ciclo natural da vida. A utilização do tratamento fútil, da obstinação terapêutica não traz benefício para o paciente, apenas prolonga a dor e sofrimento seu e de sua família.

O objetivo deste trabalho é a compreensão de como a prática da distanásia, a obstinação terapêutica, o tratamento inútil gera uma lesão aos direitos fundamentais, ou seja, como essa prática fere os princípios da dignidade da pessoa humana, da liberdade, da autonomia da vontade.

Trata-se de um estudo realizado por meio de revisão bibliográfica e documental, descritivo e explicativo, em livros, revista e periódicos especializados. Pesquisas bibliográficas que retratam a prática da distanásia, e como esta prática gera uma lesão aos direitos fundamentais, como a dignidade da pessoa humana, pois, prolongar a vida sem ter 
uma perspectiva de cura, gera apenas dor e sofrimentos a todos que estão em contato direto e indireto com esta situação.

\section{OS AVANÇOS TECNOLÓGICOS E A MORTE DIGNA}

Os avanços das práticas médicas, no século $\mathrm{XX}$, especialmente no campo da tecnologia, áreas cirúrgicas, terapêutica, aprimoramento profissional gerou inúmeros benefícios para este campo. Estes avanços proporcionaram o controle ou a eliminação de doenças, porém gerou diminuição no número de mortes naturais, ou seja, introduziu o prolongamento desnecessário da vida, a submissão de pacientes a tratamentos injustificáveis e a obstinação terapêutica ${ }^{3}$ a qualquer custo (MACHADO et al., 2007, p. 35). Pensamento que corrobora com o de Esdra Cabus Moreira e João Guilherme Biehl (2004, p. 26), com o entendimento de que os avanços tecnológicos e científicos permitiram um controle das funções fisiológicas do paciente, podendo prolongar a sua vida.

O fim da vida vem relacionado a sentimentos ligados a derrota, perda, impotência, fracasso. E com esse avanço técnico-científico, o avanço na pesquisa biomédica, o estado da arte forneceu ao médico a possibilidade de adiar o processo da morte (SILVA, 2015, p. 101).

Assim, esses avanços empregados na área da saúde, por um lado, proporcionam uma melhoria na qualidade de vida das pessoas, por outro lado, a sobrevida ocasiona um prolongamento desnecessário da vida, gerando, em certos casos, angustia, dor, sofrimento para o paciente, seus familiares e inclusive profissionais de saúde.

O ser humano intervindo nos processos biológicos do indivíduo, passa a relativizar o seu ciclo de vida natural, controla a sua vida, ampliando ou reduzindo o seu tempo. Neste aspecto é importante a compreensão dos princípios da qualidade de vida e da sacralidade de vida, que embora antagônicos, se complementam diante de conflitos éticos. Em relação ao princípio da qualidade de vida, tem como objetivo promover o bem-estar de seu titular,

\footnotetext{
${ }^{3}$ Pessini (2003, p. 389) afirma que: Na luta pela vida, em circunstâncias de morte iminente e inevitável, a utilização de todo arsenal tecnológico disponível sem critérios éticos traduz-se em obstinação terapêutica que facilmente nega a dimensão da finitude e da mortalidade humanas.
} 
buscar a sua qualidade de vida, minorar o sofrimento, ainda que haja a necessidade de interferir diretamente na vida (SCHRAMM, 2009, p. 377).

No princípio da sacralidade de vida, a vida é indisponível, inclusive, para o sujeito daquela vida específica, ou seja, deve-se respeitar o finalismo intrínseco da natureza, os desígnios divinos, sem se opor a estes. Nenhuma intervenção pode ser realizada na vida, de modo independente de seus propósitos (SCHRAMM, 2009, p. 377). Segundo Matheus Massaro Mabtum e Patrica Borba Marchetto (2015, p. 58-59), vivemos em uma fase de transição. Antigamente prevalecia o princípio da sacralidade de vida, em que a vida era considerada um bem supremo, indisponível, absoluto. Já na visão atual prevalece a o princípio da qualidade de vida, sendo a qualidade de vida, muitas vezes, superior a própria vida.

Diante do conflito destes princípios surgem alguns questionamentos, até quando investir em tratamentos? Quando interrompê-los? Até quando o homem pode interferir no ciclo da vida do indivíduo? É ético prolongar a vida do paciente ocasionando um aumento em sua dor? O que é uma morte digna? Questões que geram polêmicas, que possuem respostas amplas, sem um entendimento concreto na sociedade, em que prevalece o entendimento subjetivo de cada indivíduo.

Diante desta visão e para compreender o tema, a princípio é necessário compreender, diferenciar e analisar alguns termos relacionados ao tema: eutanásia, ortotanásia, distanásia, mistanásia. Em uma visão holística os termos podem parecer sinônimos, porém, há diferenças. Apensar de a eutanásia ser um dos termos mais conhecidos e debatidos, ainda existem dúvidas sobre a sua conceituação precisa. Rodrigo Siqueira Batista e Roland Scharamm (2004, p. 858) explicam que o termo eutanásia ${ }^{4}$ é originário do grego, sendo traduzido como boa morte, sendo os radicais eu, que corresponde a com bondade, com benevolência, de bem, e thanatos, que corresponde à morte.

\footnotetext{
${ }^{4}$ A expressão "eutanásia", tal como entendida no mundo moderno, é classicamente imputada ao filósofo e político inglês Francis Bacon, que teria usado no século XVII, concebendo-a como a conduta médica que assegura ao paciente, quando já não existe esperança de cura, uma morte tranquila e doce (HOTTOIS; PARIZEAU, 1998).
} 
Portanto, a eutanásia consiste em uma antecipação voluntária do passamento, dirigida à suspensão de um sofrimento insuportável. É “o emprego ou a abstenção de procedimentos que permitem apressar ou provocar o óbito de um doente incurável, a fim de livrá-lo dos extremos sofrimentos que o assaltam", segundo Hubert Lepargneur (1999, p. 43). Já o termo ortotanásia, segundo Luís Roberto Barroso e Letícia de Campos Velho Martel (2011, p. 107), consiste na morte em seu tempo certo, sem tratamentos desproporcionais, ou seja, sem a utilização de métodos extraordinários e desproporcionais, que são utilizados na distanásia, e sem a abreviação do processo de morrer. É a aceitação da morte, para que ela siga o seu curso natural.

Em uma visão mais recente, a ortotanásia consiste em suspender os tratamentos extraordinários e manter os secundários, como a alimentação e os cuidados paliativos ${ }^{5}$, a fim de evitar a dor (ASCENSÃO, 2009, p. 431). Mistanásia - termo originário do grego, sendo os radicais mis, com significado de miserável, e thanatos, com a ideia de morte consiste na morte prematura, abandonada, fora e/ou antes do seu tempo. Tem referência à morte de milhares de pessoas sem nenhuma assistência, deixadas em lixões, em ruas, pontes, uma de suas formas mais estudadas é a falta de assistência à saúde, em hospitais com corredores lotados, com pacientes abandonados pelo Estado e por todos (MENDONÇA; SILVA 2014, p. 175).

Consequentemente, a Mistanásia consiste em umas das piores modalidades de processo que envolve a morte, não há o respeito ao processo natural do fim da vida, a vida é ceifada abruptamente por falta de assistência do Poder Público, ocorre por abandono, descasos. A morte digna, portanto, é difícil de ser conceituada, pois, é subjetiva e cabe a cada pessoa escolher e decidir o que seria para ela, o morrer com dignidade. O termo distanásia, por ser o foco deste trabalho, será especificado no próximo capítulo.

\footnotetext{
${ }^{5}$ Cuidado Paliativo é uma abordagem que promove a qualidade de vida de pacientes e seus familiares, que enfrentam doenças que ameacem a continuidade da vida, através da prevenção e alívio do sofrimento. Requer a identificação precoce, avaliação e tratamento da dor e outros problemas de natureza física, psicossocial e espiritual. (WHO, 2011).
} 


\section{A DISTANÁSIA}

O termo distanásia contém a ideia de dupla morte - tendo os radicais os seguintes significados, dis, de duas vezes, e thanatos, a ideia de morte - daí surge à ideia de dupla morte (SIQUEIRA-BATISTA; SCHRAMM, 2004, p. 858). A palavra foi proposta por Morcache, em 1904, e pode ser entendida como a manutenção da vida por meio de tratamentos desproporcionais que ocasiona um sofrimento físico e psicológico prolongado (SIQUEIRABATISTA, 2001, p.19). É a obstinação terapêutica, a futilidade médica.

A distanásia pode ser entendida como a forma de prolongar a vida, sem perspectiva de cura, de forma artificial. É a obstinação terapêutica, que tem como interface tanto as novas tecnologias aplicadas à medicina, com o intuito de manter as funções biológicas, como o desejo arcaico humano de superar a morte (SIQUEIRA-BATISTA; SCHRAMM, 2004, p. 32).

Rodrigo Siqueira Batista e Roland Schramm (2005, p. 114) definem que é "um aprofundamento das características que tornam, de fato, a morte uma espécie de hipermorte".

Logo, a distanásia acaba por adiar a morte ao máximo possível, empregando todos os meios disponíveis, ordinários e extraordinários, mesmo que estes tratamentos ocasionem um aumento da dor e do sofrimento tanto do próprio indivíduo como, também, de sua família. É um processo que quebra o processo/ciclo natural da morte, pois prolonga - por uma, duas semanas e, às vezes, até meses - uma vida que não tem mais perspectiva, ou seja, em que a morte é inevitável e iminente.

A distanásia, portanto, não respeita o princípio da dignidade da pessoa humana, previsto na constituição federal brasileira, pois o tratamento, que não leva a cura e nem a sobrevida digna, acaba por ocasionar mais dor e sofrimento do que a própria doença. Diante do exposto, surge o questionamento até quando é ético evitar a morte a qualquer custo, trazendo mais sofrimento para quem não tem mais uma perspectiva de vida, quebrando o seu ciclo natural da morte?

Diante da necessidade de dirimir eventuais conflitos, em relação ao prolongamento da vida independente do estado em que se encontra e do respeito à dignidade humana, a 
liberdade e a autonomia da vontade é necessário compreender e analisar sobre a terminalidade de vida, assunto que será discutido no próximo capítulo.

\section{A VIDA E A TERMINALIDADE DE VIDA}

Antes de interpretar sobre a terminalidade de vida, é preciso entender o que é a vida. A vida comporta tanto elementos materiais (físicos e psíquicos), como imateriais (espirituais), é a fonte primária de todos os outros bens jurídicos, sendo, portanto, o direito à vida decorrente da própria natureza do homem (MARTINS, 2005, p. 269).

A vida apresenta diversos componentes, sendo eles: biológico, que corresponde as reações físico-químicas que ocorrem no organismo; o psicológico, que se enquadra na condição emocional; e o social, que diz respeito as relações interpessoais. O equilíbrio humano ocorre quando há uma harmonia entre os três componentes, quando um desses se encontra abalado, o ser humano fica fragilizado (ALMEIDA, 2012, p. 54).

Viver não é, necessariamente, a mesma coisa que estar vivo. Viver é determinado pelo conjunto dos elementos que compõem o ser humano, enquanto estar vivo remete apenas ao elemento biológico (ALMEIDA, 2012, p. 54). Logo, é possível manter uma pessoa viva por meio de um suporte de vida artificial permanente, ou seja, está presente o seu componente biológico, mas apenas em razão de um suporte artificial; porém, os componentes psicológicos e sociais já não existem mais e não são capazes de se reestabelecer, tendo em vista o seu quadro clínico.

A manutenção do componente biológico do indivíduo - não se pode mais falar em vida, pela falta dos outros componentes - se mantém apenas em razão do desejo daqueles que Ihe têm afeto e não pelo ciclo natural da vida. Imperioso torna-se o questionamento sobre o que é a terminalidade de vida? Até quando se deve manter a vida, de forma artificial? A vida é uma faculdade ou um dever? Após analisado o conceito de vida e surgindo estes questionamentos, para tentar dirimi-los é necessário compreender o conceito de terminalidade de vida que será discutido abaixo.

O conceito de terminalidade de vida, segundo Marília Campos Telles e Antônio Carlos Coltro (2010, p. 290-291), consiste em: 
A terminalidade da vida é uma condição diagnosticada pelo médico diante de um enfermo com doença grave e incurável: há, portanto, uma "doença em fase terminal" e não um "doente terminal" e assim a prioridade deve ser a pessoa doente não mais o tratamento da doença, buscando o bem-estar físico e emocional do paciente.

O paciente terminal, ou seja, aquele que está em terminalidade de vida, é aquele considerado em fase final de evolução de sua doença, sem condições de cura, mesmo que parcial ou temporária, frente a qualquer medida terapêutica conhecida. $\mathrm{O}$ indivíduo quando se encontra nesta fase, deve ser submetido aos cuidados paliativos que proporcionem ao máximo o seu conforto e bem-estar até o óbito (SILVA; SCHRAMM, 2007, p. 22).

Logo, quando constatado que a doença que acomete o indivíduo é uma doença grave e incurável, que o tratamento vai lhe causar mais dor e sofrimento e não vai the trazer uma sobrevida, é necessário se preocupar com o indivíduo em si, buscar cuidados que aliviem a sua dor e proporcionam a sua qualidade de vida, com o intuito de preservar o seu bem-estar. E não, preocupar-se com a doença e o seu tratamento.

\section{A DISTANÁSIA E A LESÃO AOS DIREITOS FUNDAMENTAIS}

Os limites de caráter ético e moral, quando analisados sob a perspectiva do exercício do direito de antecipação do fim da vida em pacientes terminais, ou seja, o da não realização da distanásia, está fundamentado primordialmente a prevalência dos direitos humanos. Os direitos humanos, por sua vez encontram-se baseados no valor supremo da dignidade da pessoa humana. (BARROSO, 2010, p. 12).

A constituição federal brasileira de 1988 , em seu artigo $3^{\circ}$, inciso III, confere a dignidade da pessoa humana o status de fundamento da República. A partir de uma simples analise, é possível constatar que a dignidade da pessoa humana atinge, na Constituição Federal, um status superior a qualquer outra disposição legal (ALBUQUERQUE FILHO, 2016, p. 194). Observe o que discorre José Afonso da Silva, sobre a dignidade da pessoa humana (SILVA, 1998, p. 91):

a dignidade da pessoa humana não é uma criação constitucional, pois ela é um desse conceitos a priori, um dado preexistente a toda experiência especulativa, tal como a própria pessoa humana. A Constituição, reconhecendo a sua existência e a 
sua eminência, transformou-a num valor supremo da ordem jurídica, quando a declara como um dos fundamentos da República Federativa do Brasil constituída em Estado Democrático de Direito.

Assim, todo o direito elencado na Constituição Federal deve garantir a dignidade do homem, pois este é considerado um fundamento da República Federativa do Brasil. Analisado de forma sucinta o princípio da dignidade da pessoa humana, é preciso analisalo de acordo com o contexto de estudo. O fundamento da República Federativa do Brasil, dignidade da pessoa humana, supera, portanto, a própria vida, atingindo a esfera da morte (ALBUQUERQUE FILHO, 2016, p. 197).

Desta forma, a distanásia, a obstinação terapêutica, a futilidade médica afronta o princípio da dignidade da pessoa humana. Esta afronta é verificada no momento em que se prolonga uma vida - em que a morte é inevitável e invencível - não podendo mais esta ser vivida de forma digna, tornando o seu fim doloroso e com sofrimento. A liberdade é considerada como um direito fundamental. Encontra-se disposta no caput do artigo $5^{\circ} \mathrm{da}$ Constituição Federal. Segundo José Afonso da Silva (2008, p 233) "a liberdade consiste na possibilidade de coordenação consciente dos meios necessários à realização da felicidade pessoal".

O princípio da autonomia decorre do próprio exercício da liberdade. A autonomia da vontade tem como pressuposto a liberdade dos indivíduos para agir de acordo com sua vontade, ou seja, para ser garantida a autonomia, o indivíduo deve ser ator principal para decidir de que forma tomará suas decisões (ALBUQUERQUE FILHO, 2016, p. 199). Ocorre que os princípios da liberdade e da autonomia são resguardados durante toda a vida do indivíduo, porém, no momento do fim da vida eles são retirados do indivíduo, seja por razões éticas, morais ou religiosas.

Assim, no fim da vida diante de um uma doença de caráter irreversível e incurável, muitas vezes, a última vontade do indivíduo é que não se realize a obstinação terapêutica, o tratamento inútil, que apenas lhe causará dor. A vontade do indivíduo é a de que a vida siga o seu ciclo natural e que seja resguardado a sua qualidade de vida por meio dos cuidados paliativos, porém não é sempre que isso acontece. 
Em um estudo de Clarissa Pires Pereira e Sandra Ribeiro de Almeida Lopes (2014, p. 58) em que foi analisado o processo de morrer no cotidiano de profissionais de saúde em Unidade de Terapia Intensiva pode se verificar a dificuldade destes profissionais em lidar com a morte, sendo que um dos entrevistados relacionou o óbito de paciente como um grande desgaste e ainda citou a dificuldade em dar a notícia de um mau prognóstico ou de morte.

Um entrevistado ainda comentou que o assunto da morte não é muito comentado entre os colegas com o intuito de manter um ambiente mais saudável, menos denso (PEREIRA; LOPES, 2014, p. 58). Mas o fato de não conversar com os colegas sobre o assunto morte - assunto que gera sofrimento, reflexão- não evita o sofrimento destes profissionais, apenas ocorre um mascaramento de tais questões.

Há falta de comunicação sobre a questão da morte, no contexto do trabalho, entre os profissionais da área da saúde, não proporciona à troca de experiências e de sentimentos, o que dificulta os profissionais a lidarem com esta questão. A relação destes profissionais com a morte deveria ser discutida de forma mais intensa na graduação, pois eles irão conviver diretamente com a morte em seu dia-a-dia de trabalho (PEREIRA; LOPES, 2014, p. 60).

Uma frase de Maria Julia Kovács é a de que "Prolongar a vida em UTIs é uma praga moderna", esta frase demonstra o despreparo dos profissionais da área da saúde, principalmente dos que lidam diretamente com a morte e com o sofrimento. Demonstra que a morte é vista como um fracasso profissional daquele que não conseguiu evitá-la (PROLONGAR, 2018).

Desta forma, os profissionais que lidam com a questão da morte devem ter uma formação voltada para aprender a lidar com estas questões, é preciso fornecer informações e instrui-los sobre o processo de morrer, além de descontruir a visão de que aquele que não conseguiu evitar a morte, fracassou. A visão de que a morte deve ocorrer de forma digna, devendo ser respeitada a autonomia do paciente.

É necessário preservar o direito de morrer dignamente que consiste na possibilidade de reivindicar vários direitos - como dignidade da pessoa humana, a liberdade, a autonomia - no momento de sua morte. É permitir que a vida tenha 
continuidade, de forma digna, ainda que caminhe para o seu término. Deve-se receber na etapa final da vida os mesmo tratamentos e cuidados que na fase inicial (BORGES, 2001, p. 284).

E da mesma forma, a realização do tratamento considerado fútil e doloroso vai contra todos os princípios fundamentais da ética médica, como verificado no estudo realizado por Almir Galvão Vieira Bitencourt e colaboradores (2017, p. 142):

Continuar um tratamento considerado fútil e doloroso é contra todos os princípios fundamentais da ética médica: contra a beneficência, pois não provê nenhum benefício ao paciente; contra a não-maleficência, pois pode causar sofrimento e prejuízo ao paciente; contra a justiça, pois exige custos, tempo e energia que poderia ser mais bem usadas em outros pacientes; e até mesmo contra a autonomia, pois ninguém quer receber uma terapia fútil que simplesmente prolonga por horas ou dias a morte (inevitável) em estado vegetativo irreversível, sem acrescentar qualidade de vida.

Assim, a realização da distanásia em um paciente é um desrespeito aos princípios da dignidade da pessoa humana, da liberdade e da autonomia, é preciso resguardar o direito a morte digna, sem dor, sem sofrimento, que siga o ciclo natural da vida. A utilização do tratamento fútil, da obstinação terapêutica não traz benefício para o paciente, apenas prolonga a dor e sofrimento seu e de sua família.

\section{CONCLUSÃO}

Diante do trabalho apresentado, é possível concluir que a prática da distanásia, da obstinação terapêutica, do tratamento inútil aumentou com os avanços tecnológicos do século $X X$, o que gera um aumento da dor e sofrimento do indivíduo e de sua família. A prática da distanásia leva a uma lesão aos direitos fundamentais, principalmente uma lesão aos princípios da dignidade da pessoa humana, da liberdade, da autonomia.

Ao prolongar a vida de uma pessoa que não tem uma perspectiva de cura, sendo a sua morte inevitável e invencível, ocorre um desrespeito à dignidade humana, que deve ser resguardada em todos os momentos da vida; a sua liberdade de escolher se deseja ou não realizar determinado tratamento e, se sim, qual tratamento; e a autonomia, pois o indivíduo deve agir de acordo com a sua vontade, deve ser o ator principal para decidir de que forma tomará suas decisões. 
Portanto, o fato de se evitar a morte a qualquer custo, quebrando o ciclo natural da morte não leva o indivíduo a uma morte digna, muito pelo contrário, a um sofrimento e dor desnecessários para o último momento da vida. Nestes casos, é de extrema importância o respeito a autonomia da vontade, preservando, assim, a dignidade humana.

Os profissionais da área da saúde demonstram uma dificuldade em lidar com a morte, sendo esta vista como um fracasso do profissional que não conseguiu evita-la, assim, os profissionais tendem a prolongar a vida do paciente mesmo quando a morte é inevitável. Diante destes fatos é preciso que estas questões sejam discutidas de forma mais intensa na graduação, de forma a capacita-los a lidar mais facilmente com a morte.

O uso dos cuidados paliativos, visando à qualidade de vida do paciente e de seus familiares, com a identificação precoce, avaliação e tratamento da dor e outros problemas de natureza física, psicossocial e espiritual, também, são essências, pois permitem que os momentos do fim da vida sejam de qualidade, buscando diminuir a dor e o sofrimento do ser humano.

\section{REFERÊNCIAS}

AlbuQUERQUe FILHO, Flávio Cardozo de. O Direito Constitucional ao Fim da Vida de Forma Digna: Uma Análise a Partir do Biopoder. Revista da Ejuse, n. 25, 2016.

ALMEIDA, A. J. T. A ortotanásia e a lacuna legislativa. In: MABTUM, Matheus Massaro; MARCHETTO, Patrícia Borba (org.). O debate bioético e jurídico sobre as diretivas antecipadas de vontade [online]. 1. ed. São Paulo: Cultura Acadêmica, 2015.

ASCENSÃO, José de Oliveira. A terminalidade da vida. Revista Bioética e Responsabilidade. Rio de Janeiro: Editora Forense, 2009.

BARROSO, Luís Roberto. A Dignidade da Pessoa Humana no Direito Constitucional Contemporâneo: Natureza Jurídica, Conteúdos Mínimos e Critérios de Aplicação. Versão provisória para debate público. Mimeografado, dez. 2010.

BARROSO, Luís Roberto; MARTEL, Letícia de Campos Velho. A morte como ela é: dignidade e autonomia individual no final da vida. Revista do Ministério Público, Rio de Janeiro, n. 40, p. 103-139, 2011. 
BITENCOURT Almir Galvão Vieira et al. Condutas de limitação terapêutica em pacientes internados em Unidade de Terapia Intensiva. Revista Brasileira de Terapia Intensiva [Internet], v. 19, n. 2, p. 137-143, 2007. Disponível: http://www.scielo.br/scielo.php?script=sci_arttext\&pid=S0103-507X2007000200001. Acesso em: 25 mar. 2019.

BORGES, Roxana Cardoso Brasileiro. Direito de morrer dignamente: eutanásia, ortotanásia, consentimento informado, testamento vital, análise constitucional e penal e direito comparado. In: SANTOS, Maria Celeste Cordeiro Leite (org.). Biodireito: ciência da vida, os novos desafios. São Paulo: Revista dos Tribunais, 2001.

HOTTOIS, Gilbert; PARIZEAU, Marie-Hélène. Dicionário da Bioética. Lisboa: Piaget, 1998.

LEPARGNEUR, Hubert. Bioética da eutanásia: argumentos éticos em torno da eutanásia. Revista Bioética, v. 7, n. 1, p. 41-48, 1999.

MACHADO, Karina Dias Guedes; PESSINI, Leo; HOSSNE William Saad. A formação em cuidados paliativos da equipe que atua em unidade de terapia intensiva: um olhar da bioética. Revista Bioethikos - Centro Universitário São Camilo, v. 1, n. 1, p. 34-42, 2007.

MABTUM, Matheus Massaro; MARCHETTO, Patrícia Borba. 0 debate bioético e jurídico sobre as diretivas antecipadas de vontade [online]. São Paulo: Cultura Acadêmica, 2015.

MARTINS, Ives Gandra da Silva. Direito fundamental à vida. São Paulo: Quartier Latin, 2005.

MENDONÇA, Márcia Helena; SILVA, Marco Antônio Monteiro da. Vida, Dignidade e Morte: Cidadania e Mistanásia. Iusgentium, v. 9, n. 6, p. 151-190, 2014.

MOREIRA, Esdras Cabus; BIEHL, João Guilherme. Práticas médicas de aceitação da morte na UTI de um hospital geral no Nordeste do Brasil. Revista Bioética, v. 12, n. 1, p. 22-28, 2004.

PEREIRA, Clarissa Pires; LOPES, Sandra Ribeiro de Almeida. O processo do morrer inserido no cotidiano de profissionais da saúde em Unidades de Terapia Intensiva. Revista Sociedade Brasileira de Psicologia Hospitalar, v. 17, n. 2, p. 49-61, 2014.

POTTER, Van Reusselaer. Questões ética - Chave no debate hodierno sobre a distanásia. In: GARRAFA, Volnei; PESSINI Leo (org.). Bioética: poder e injustiça. São Paulo: Centro Universitário São Camilo: Loyola: Sociedade Brasileira de Bioética, 2003.

PROLONGAR a vida em UTIs é uma praga moderna, diz especialista em morte. UOLUniversa. Disponível em: https://universa.uol.com.br/noticias/redacao/2018/01/03/prolongar-a-vida-em-utis-euma-praga-moderna-diz-especialista-em-morte.htm. Acesso em: 25 mar. 2019.

SCHRAMM, Fermin Roland. O uso problemático do conceito 'vida' em bioética e suas interfaces com a práxis biopolítica e os dispositivos de biopoder. Revista Bioética, v. 17, $\mathrm{n}$. 3, p. 377-389, 2009.

SILVA, Carlos Henrique Debenedito; SCHRAMM, Fermin Roland. Bioética da obstinação terapêutica no emprego da hemodiálise em pacientes portadoras de câncer do colo do 
útero invasor, em fase de insuficiência renal crônica agudizada. Revista Brasileira de Cancerologia, v. 53, n. 1, p. 17-27, 2007.

SILVA, José Afonso da. A dignidade da pessoa humana com valor supremo da democracia. Revista de Direito Administrativo, v. 212, p. 89-94, 1998.

SILVA, José Afonso da. Curso de Direito Constitucional Positivo. 30. ed. São Paulo: Malheiros, 2008.

SILVA, José Antonio Cordero da. O fim da vida: uma questão de autonomia. Revista de Pediatria do Centro Hospitalar do Porto, v. 23, n. 2, p. 100-105, 2014.

SIQUEIRA-BATISTA, Rodrigo, SCHRAMM, Fermin Roland. A filosofia de Platão e o debate bioético sobre o fim da vida: interseções no campo da Saúde Pública. Cadernos de Saúde Pública, v. 20, n. 3, p. 855-865, 2004.

SIQUEIRA-BATISTA, Rodrigo; SCHRAMM, Fermin Roland. Eutanásia: pelas veredas da morte e da autonomia. Ciência e Saúde coletiva, v. 9, n. 1, p. 31-41, 2004.

SIQUEIRA-BATISTA, Rodrigo. O médico diante da morte: perspectivas de discussão ética com base na filosofia de Immanuel Kant. Revista da Faculdade de Medicina de Teresópolis, v. 3, p. 18-22, 2001.

SIQUEIRA-BATISTA Rodrigo; SCHRAMM, Fermin Roland. Conversações sobre a "boa morte": o debate bioético acerca da eutanásia. Cadernos de Saúde Pública, v. 21, n. 1, p. 111-119, 2005.

TELLES, Marília Campos Oliveira; COLTRO, Antônio Carlos Mathias. A morte digna sob a ótica judicial. In: PEREIRA, T. S.; MENEZES, R. A.; BARBOZA, H. H. (coord.). Vida, Morte e Dignidade Humana. Rio de Janeiro: Editora GZ, 2010. p. 277-302.

WORLD HEALTH ORGANIZATION. Cancer. WHO Definition of Palliative Care, 2011. Disponível em: http://www.who.int/cancer/palliative/definition/en/. Acesso em: 16 jul. 2018. 